\title{
Coarctation of aorta presenting as hypertensive encephalopathy in a young female
}

\author{
Sharma $S^{1}$, Pathak $A^{2}$, Acharya $S^{3}$, Shukla $S^{4}$, Banode $P^{5}$ \\ ${ }^{1}$ Dr. Sarthak Sharma Resident, ${ }^{2}$ Dr. Ashutosh Pathak, Resident, ${ }^{3}$ Dr. Sourya Acharya, Professor, above all authors are \\ affiliated with Department of Medicine, ${ }^{4}$ Dr. Samarth Shukla, Professor, Department of Pathology, ${ }^{5}$ Dr. Pankaj Banode, \\ Professor, Department of Interventional Radiology, All the authors affiliated with Datta Meghe Institute of Medical \\ Sciences (D.U), J N Medical College, Sawangi, Wardha, Maharashtra, India.
}

Address for Correspondence: Dr Sarthak Sharma, Yashoda PG Boys Hostel, Jawaharlal Nehru Medical College, Datta Meghe Institute of Medical Sciences, Sawangi, Wardha, Maharashtra, Email id: sarthak.sharma23@gmail.com

\begin{abstract}
Coarctation of Aorta (CoA) is a congenital cardiac defect which can present in adults. The usual presentation is hypertension. Though it has subtle clinical signs but they can go undetected if not sought for. One of the most catastrophic presentations can be severe hypertension with its complications. We report a case of a 40 year old female who presented to us with hypertensive encephalopathy and finally diagnosed as CoA
\end{abstract}

Key words: Coarctation of Aorta, CoA, Hypertension, Hypertensive encephalopathy

\section{Introduction}

CoA is a congenital cardiac malformation, where there is a constriction in the aorta distal to the left subclavian artery. Sometimes the constriction occurs proximal to the subclavian artery when it is called preductal CoA. The incidence of CoA is 4 in 10,000 live births. Five to eight percent of children with congenital heart disease have CoA [1].

The defect manifests in early life and is usually treated appropriately but sometimes when CoA presents in an adult, it is mainly due to re-coarctation following catheter or surgical therapy and rarely can be a case of native coarctation presenting first time in adult life. If not treated, the mean life expectancy is 35 years. Ninety percent of patients die before the age of 50 years. It can complicate as systemic hypertension, coronary heart disease, congestive cardiac failure, aortic dissection and stroke [2].

The different methods of treatment are medical therapy and surgical therapy including percutaneous angioplasty with or without stent placement.

\section{Case Report}

A 40 year old female presented to us with 2 days history of severe headache, 2 episodes of vomiting and drowsiness since 8 hours. There was history of seizure 2 hours before admission. On examination, the patient was drowsy and a bit irritable (GCS: 9), pulse- 118/min regular. Dorsalis pedis, posterior tibial and popletial pulses were not palpable. Femoral pulses were weak, no carotid bruit or thrill was detected. Radio femoral delay was present. Blood pressure was $210 / 120$ $\mathrm{mmHg}$ in right arm, 206/1 $12 \mathrm{mmHg}$ in left arm and 170/98 mmHg in left lower limb. There was no cyanosis, jugular venous pressure was normal and pedal edema was absent. Cardiovascular examination revealed normal S1 and S2. Fourth heart sound and ejection systolic murmur in the lower left sternal border were heard. Respiratory and abdominal examinations were normal. CNS- higher function: drowsy, no cranial nerve deficit, moving all four limbs, planter's bilateral extensor and no terminal neck stiffness.

Manuscript received: $11^{\text {th }}$ March 2017

Reviewed: $18^{\text {th }}$ March 2017

Author Corrected: $24^{\text {th }}$ March 2017

Accepted for Publication: $31^{\text {st }}$ March 2017 
Fundus examination revealed Grade III hypertensive retinopathy. In view of the above clinical examination, possibility of hypertensive urgency due to CoA was kept. For evaluation of seizure and headache, urgent neuroimaging was done and subarachnoid hemorrhage and stroke were ruled out.

The patient was treated with intravenous nitroglycerine $(20 \mathrm{mcg} / \mathrm{min})$ and injection hydralazine (20 mg intramuscular stat) and blood pressure was controlled to $160 / 90 \mathrm{mmHg}$ in the next 7 hours. The patient was put on tablet metoprolol 50 mg twice a day once the injectable anti-hypertensive drugs were tapered off.

Her complete blood count, kidney function test, liver function test and blood sugar levels were normal. X-ray chest showed cardiomegaly and visible biarcute appearance of aortic arch ("3" sign). ECG showed left ventricular hypertrophy with strain pattern. 2D-Echocardiography showed a peak systolic gradient of $72 \mathrm{mmHg}$ and low antigrade diastolic flow in the descending thoracic aorta in a classical saw tooth pattern which was highly specific for aortic obstruction.

Peripheral angiography was done by placing a sheath in the femoral artery and dye was injected which revealed coarctation distal to left subclavian artery with post stenotic dilatation of descending aorta. (Fig 1)

Considering the presence of high gradient coarctation with severe hypertension, the patient underwent balloon angioplasty with stent placement.

Immediately after the stent placement, the lower limb pulses were easily palpable. The blood pressure came back to normal decreasing the dose of antihypertensive within 6 days. The patient was discharged after 7 days and is awaiting follow up after 3 months. She was given tablet clopidogrel $75 \mathrm{mg}$ and tablet Aspirin $150 \mathrm{mg}$ for 3 months at the time of discharge.

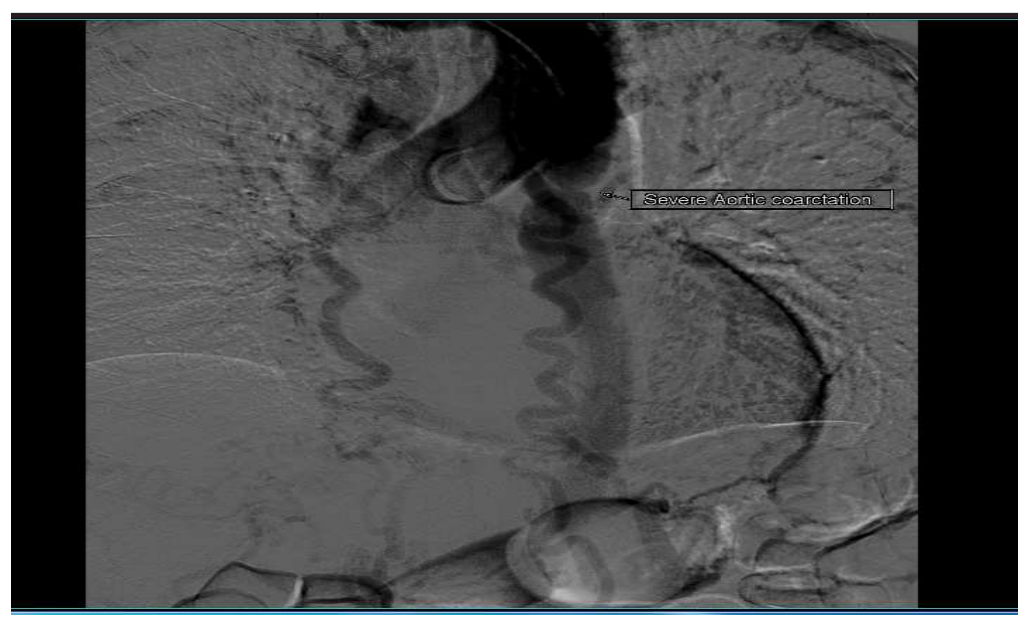

Fig 1: CoA distal to left subclavian artery (small black arrow) with post stenotic dilatation of descending aorta

\section{Discussion}

CoA is characterized by discreet narrowing of thoracic aorta distal to left subclavian artery. The defect imposes significant afterload on the Left Ventricle resulting in wall stress, compensatory left ventricular hypertrophy, left ventricular dysfunction and collateral formation.

CoA in adults usually presents as systemic hypertension and discrepancy between upper limb and lower limb blood pressure as in our case. The peculiarity of our case is hypertensive encephalopathy which is a medical catastrophe.
The 2008 American Heart Association/American College of Cardiology guidelines for intervention in CoA includes peak to peak coarctation gradient $>=20$ $\mathrm{mmHg}$ or peak to peak coarctation gradient $<20 \mathrm{mmHg}$ in presence of anatomic imaging revealing significant coarctation. The European society of cardiology recommends early treatment in all patients with a noninvasive pressure difference of more than $20 \mathrm{mmHg}$ in upper and lower limbs regardless of symptoms but with upper limb hypertension of > 140/90 $\mathrm{mmHg}$ and significant left ventricular hypertrophy [3]. 
Surgical repair of coarctation is achieved by resection with end to end anastomosis [4,5]. Aneurysm formation is a common complication of surgical therapy. Sometimes aortic dissection may occur late after surgical repair. Morbidity includes paradoxical hypertension, hoarseness of voice, diaphragmatic palsy and subclavian steel syndrome.

Balloon angioplasty was introduced in 1982 and is currently done with or without stent deployment. It is the preferred treatment modality in native coarctation in adults or re-coarctation after surgery [6]. There is an increase incidence of aneurysm and restenosis after balloon angioplasty.

Stenting of CoA was introduced in the 1990 using bare metal stents. Acute mortality with this procedure is 0 $3 \%$ [7]. Acute aortic dissection may be seen in $13 \%$ of cases [8]. Biodegradable stents are an area of research $[9,10]$.

The best method of repair of CoA is based on several factors. Though stent implantation carries the lowest morbidity, repeated interventions may be required as compared to surgery. Endovascular therapy is currently the treatment of choice, when there is ventricular dysfunction and other comorbidities like diabetes and ischemic heart disease are present [7].

Drugs that are used to control the hypertension are beta blockers, angiotensin converting enzyme inhibitors and angiotensin receptor blockers [3]. Survival of the patients with CoA has dramatically improved after surgical repair became available.

\section{Conclusion}

CoA is a congenital cardiac malformation that can go undiagnosed. Hypertension in a young individual should raise a suspicion of $\mathrm{CoA}$ and it should be sought for. Nowadays different surgical and interventional treatment are available but these modalities should be individualized for each patient.

\section{Funding: Nil, Conflict of interest: None Permission of IRB: Yes}

\section{References}

1. Hoffman JI, Kaplan S. The incidence of congenital heart disease. J Am Coll Cardiol. 2002 Jun 19;39 (12): 1890-900.
2. Warnes CA, Williams RG, Bashore TM, Child JS, Connolly HM, Dearani JA, Del Nido P, Fasules JW, Graham TP Jr, Hijazi ZM, Hunt SA, King ME, Landzberg MJ, Miner PD, Radford MJ, Walsh EP, Webb GD. ACC/AHA 2008 Guidelines for the Management of Adults with Congenital Heart Disease: Executive Summary: a report of the American College of Cardiology/American Heart Association Task Force on Practice Guidelines (writing committee to develop guidelines for the management of adults with congenital heart disease). Circulation. 2008 Dec 2;118(23):2395451. doi: 10. 1161/ CIRCULATIONAHA.108.190811. Epub 2008 Nov 7.

3. Baumgartner $\mathrm{H}$, Bonhoeffer $\mathrm{P}$, De Groot NM, de Haan F, Deanfield JE, Galie N, Gatzoulis MA, GohlkeBaerwolf C, Kaemmerer H, Kilner P, Meijboom F, Mulder BJ, Oechslin E, Oliver JM, Serraf A, Szatmari A, Thaulow E, Vouhe PR, Walma E; Task Force on the Management of Grown-up Congenital Heart Disease of the European Society of Cardiology (ESC); Association for European Paediatric Cardiology (AEPC); ESC Committee for Practice Guidelines (CPG). ESC Guidelines for the management of grown-up congenital heart disease (new version 2010). Eur Heart J. 2010 Dec; 31(23):2915-57. doi: 10.1093/eurheartj/ehq249. Epub 2010 Aug 27.

4. Gatzoulis MA, Swan L, Therriern J. Adult congenital heart disease : A practical guide. Blackwell Publishing; 2006.

5. Manganas C, Iliopoulos J, Chard RB, Nunn GR. Reoperation and coarctation of the aorta: the need for lifelong surveillance. Reoperation and coarctation of the aorta: the need for lifelong surveillance. Ann Thorac Surg. 2001 Oct;72(4):1222-4.

6.Lorber A, Ettedgui JA, Baker EJ, Jones OD, Reidy J, Tynan M. Balloon aortoplasty for recoarctation following the subclavian flap operation. Int $\mathrm{J}$ Cardiol. 1986 Jan;10(1):57-63.

7. Anagnostopoulos-Tzifa A. Management of aortic coarctation in adults: endovascular versus surgical therapy. Hellenic J Cardiol. 2007 Sep-Oct;48(5):290-5.

8. Hamdan MA, Maheshwari S, Fahey JT, Hellenbrand WE. Endovascular stents for coarctation of the aorta: initial results and intermediate-term follow-up. J Am Coll Cardiol. 2001 Nov 1;38(5):1518-23. 
9. Forbes TJ. Intermediate follow-up following intravascular stenting for treatment of coarctation of aorta. Catheter Cardiovasc Interv. 2007;70:569-577.
10. Peters B, Ewert P, Berger F. The role of stents in the treatment of congenital heart disease: Current status and future perspectives. Ann Pediatr Cardiol. 2009 Jan; 2 (1): 3-23. doi: 10.4103/0974-2069.52802.

\section{How to cite this article?}

Sharma S, Pathak A, Acharya S, Shukla S, Banode P. Coarctation of aorta presenting as hypertensive encephalopathy in a young female. Int J Med Res Rev 2017;5(03):320-323 doi:10.17511/ijmrr. 2017.i03.17. 